\title{
One Power Control Strategy of Wind Farm Based on the Battery Energy Storage
}

\author{
Haiping He ${ }^{a}$, Jiang $\mathrm{Cao}{ }^{b}$, Yu Sun ${ }^{c}$, Qinglin Bo ${ }^{d}$, Lei Li e and Xuemei Yang ${ }^{f}$ \\ Chuzhou power supply company of Anhui Province, Chuzhou, Anhui 239000, China \\ ahehaiping208@126.com, b20773245@qq.com, c115356017@qq.com, d1132655049@qq.com, \\ e416194511@qq.com, f541060166@qq.com
}

Keywords: Wind Power Prediction, Battery Energy Storage, Smooth Control, Peak Shaving, Hybrid Power Control.

\begin{abstract}
Power output control of wind farm is an important way of improving the wind farm performance and enhancing the ability of power grid to connect wind farm. In allusion to the power fluctuation caused by large-scale integration of wind power, this paper proposes a power smooth control strategy of battery energy storage based on the hybrid power prediction. This control strategy has constructed the dynamic reference active currents according to the hourly forecast results of wind power and demand of load power. By tracking active currents of battery energy storage system, the smooth control of wind power output will be realized, and can respond to the power balance demand of the system as well. The effectiveness and practicability of the proposed control strategy are shown by the simulation results.
\end{abstract}

\section{Introduction}

The operation of grid-connected wind farms is an effective way for the large-scale utilization of wind energy. However, the power output depends on wind speed which is random and uncontrollable. With a high penetration of wind power system for the grid, the influence of wind power fluctuation on the grid is more remarkable [1]. The increasing amplitude of peak-valley difference of grid's equivalent load and anti-peaking characteristics of wind power both further increase the need of peak shaving capacity of system [2], which results in that the contradiction between system's power supply and load demand increases sharply. This brings the current situation and major problems in the power system dispatching operation [3]-[4]. To release the pressure of peak shaving and frequency modulation of power system, and improve the utilization of wind energy and the economic benefit of wind farm, our country has developed and installed wind power prediction systems [5]. However, the error of prediction's mean square root of various timescale is approximately $20 \%$ [6] at present, which is difficult to meet the demand of system's dispatch. Consequently, it has become a hot subject in recent years to make use of battery energy storage system to control the power output of wind farm.

Based on hourly forecast results of wind power and load demand of system, this paper puts forward a control strategy which combines the direct current control with smooth and peak shaving control of wind power output. It can reach the goal of smooth control of wind farm's power output, and also respond the requirement of system's power balance. This control strategy provides a new effective method for analyzing the capacity configuration and model of wind energy storage system.

\section{Battery Energy Storage System (BESS) Configuration and Modeling}

\subsection{BESS Configuration}

Fig. 1 outlines the structure of the examined battery energy storage system (BESS). It includes a lithium battery system, bi-directional DC/DC chopper circuit, bi-directional AC/DC converter, control devices and transformers. 


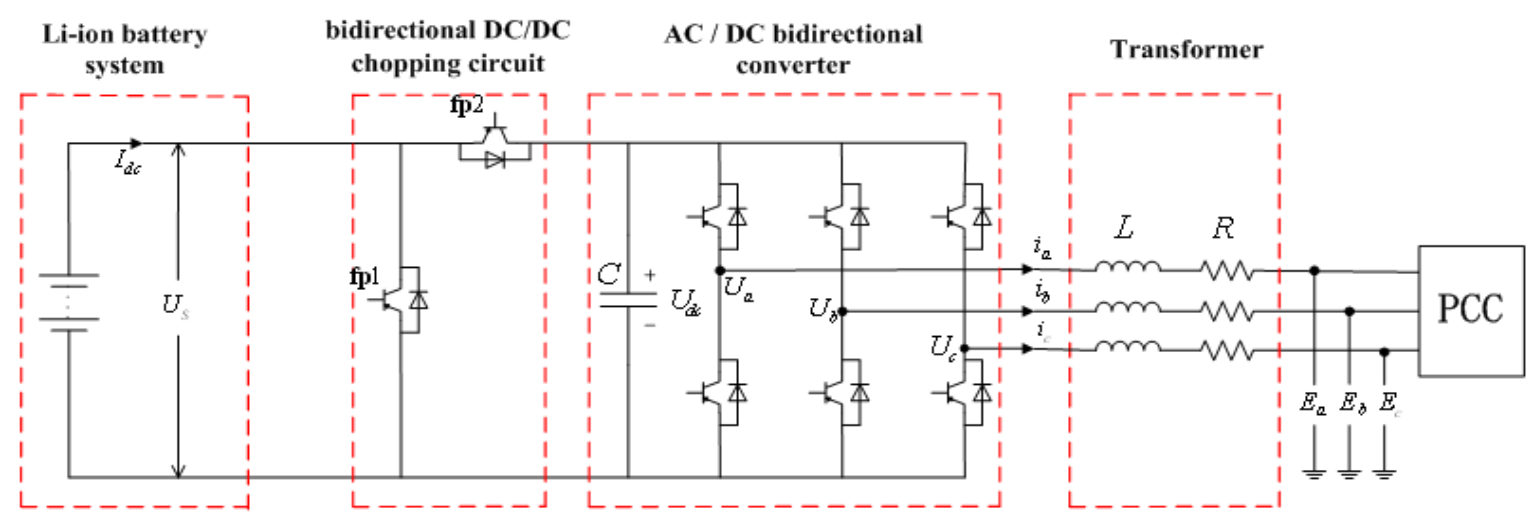

Figure 1. Structure of battery energy storage system (BESS).

As shown in Fig.1, Bi-directional DC/DC chopper circuit provides a good interface for battery to meet the requirements of the battery voltage while charging and discharging, to improve battery life. $\mathrm{AC} / \mathrm{DC}$ converter can achieve the energy bi-directional flow between ac system and lithium battery system.

Where, $\mathrm{R}$ is the equivalent resistance of the transformer while in series and line loss; $L$ is the equivalent inductance of the transformer series inductance; $C$ is filter capacitor in DC side; $E_{a}, E_{b}, E_{c}$ are the three-phase voltages at the point of common connection( PCC); $U_{a}, U_{b}, U_{c}$ are the three-phase voltages of inverter in AC side; $i_{a}, i_{b}, i_{c}$ are the three-phase line currents of inverter in AC side; $U_{d c}$ is terminal voltage of filter capacitor in DC side; $R_{S}, U_{s}$ present battery equivalent resistance and terminal voltage, respectively; $I_{d c}$ is output current of battery; fp1 and fp2 are control switch signals of bi-directional DC/DC chopper circuit.

\subsection{Modeling of li-ion Battery}

A model of lithium battery (High energy lithium-ion (li-ion) cell VL 45E cell) is used while simulating and modeling in this paper. The relationship between open voltage and released capacity of battery is given as expression (1).

$$
V=4-0.002 \times I-a+b \times \ln \left(C_{F}\right)-e \times C_{F}-d \times \ln \left(C_{F} /\left(R-C_{F}\right)\right)
$$

Where, $I$ is the battery discharge current (A), $C_{F}$ released capacity (Ah) of battery; a, b, e, d, R are parameters relative to I, respectively.

\subsection{Modeling and Control of Bi-directional DC/DC Chopper Circuit}

Fig. 1 is the bi-directional DC/DC chopper circuit. If fp1 works in PWM mode and fp2 is turned off as a diode, this circuit is Boost circuit, which is used in battery charging. In turn, it is a Buck circuit for battery discharging. Therefore, to achieve bi-directional flow of DC/DC converter power, fp1 and fp2 are controlled to work in a complementary mode. As shown in Fig.2, the control structure of bi-directional DC/DC chopper circuit is working as a Boost circuit, which adopts double closed loop control of outer voltage loop and inner current loop, and the reference value of controlled battery's terminal voltage $U_{\text {sref }}$ is $0.22 \mathrm{kV}$.

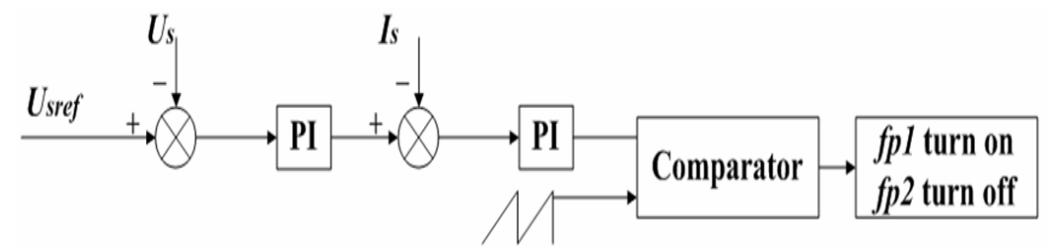

Figure 2. Control of bi-directional DC/DC chopping circuit under Boost mode 


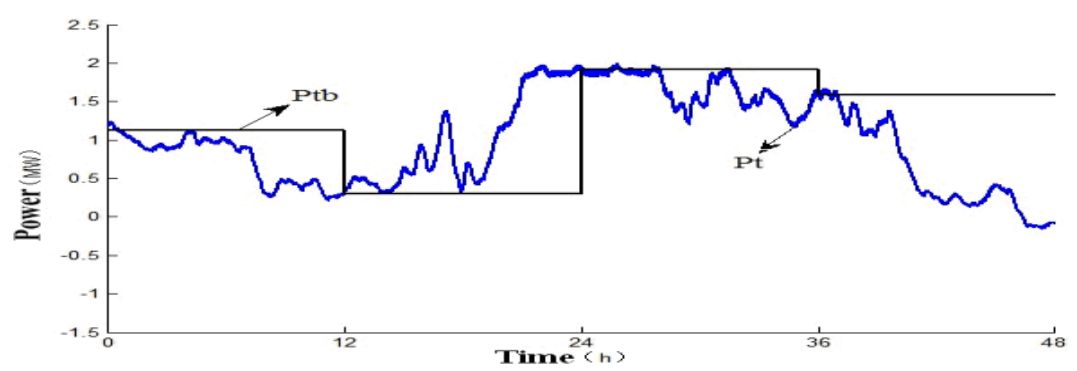

Figure 3. A certain wind farm 2MW wind generator's power output within 48 hours

\section{The Power Output Control Strategy of Wind Farm Based on The Battery Energy Storage}

\subsection{The Fluctuation Rate of Wind Farm Active Power Output}

The influence of wind power on the grid is mainly caused by power fluctuations. This paper defines the wind power fluctuation rate (smoothness) over a given period of time is shown in

$$
\beta=\frac{P_{t \max }-P_{t \min }}{P_{t b}} \times 100 \%
$$

Where, $P_{t b}$ is the reference value of the power output of the wind power within a cycle, $P_{t \text { max }}$ and $P_{t \text { min }}$ are the maximum power and minimum power values in this period, respectively. Set $P_{t b}=0.5\left(P_{t \text { max }}+P_{t \text { min }}\right)$, Then $P_{t \text { max }}=(1+0.5 \beta) P_{t b}, P_{t \text { min }}=(1-0.5 \beta) P_{t b}$.

Fig. 3 is the active power generated by a wind farm with a $2 \mathrm{MW}$ wind power generator within 48 hours. $P_{t b}$ is the smooth power reference value of 12-hour forecast period, and measured power $P_{t}$ fluctuates obviously in this period of time. Based on above curve and equation (2), we calculate maximum fluctuation rate within 12 hours, and then reduce the forecast period to $8,6,4,2,1$ hour, respectively. The maximum fluctuation rates of corresponding cycle are listed in Tab. I. Data in Tab.1 show that, the maximum fluctuation rates present a decreasing trend with the decrease of the observed time cycle. Tab. 2 lists hourly power fluctuation rate of the power output of wind farm under smooth control with no power prediction. Most of data are more than $20 \%$, even up to $83.1 \%$. If the wind farm was seen as a negative load, the active power fluctuation rate of wind farm should be limited in the range of $20 \%$, according to the dispatching requirements of the regional power grid.

Table 1. The maximum fluctuation rates in different cycles of a certain wind farm

\begin{tabular}{|c|c|c|c|c|c|c|}
\hline The cycle of time period (h) & 12 & 8 & 6 & 4 & 2 & 1 \\
\hline Maximum fluctuation (\%) & 150 & 129.8 & 126.2 & 116 & 102.3 & 83.1 \\
\hline
\end{tabular}

\subsection{The smooth control strategy based on wind power prediction}

Random fluctuations of wind power adversely affect the normal operation and dispatch of the grid. If the hourly wind power forecast in the future could be provided to the dispatching center of the grid, this kind of influence would be greatly

Table 2. Hourly fluctuation statistics of a wind farm under smooth control with no power prediction reduced.

\begin{tabular}{|c|c|c|c|c|c|c|c|}
\hline $\begin{array}{c}\text { Time } \\
\text { series }(\mathrm{h})\end{array}$ & $\begin{array}{l}\text { No predi- } \\
\text { ction }\end{array}$ & $\begin{array}{c}\text { Time } \\
\text { series(h) }\end{array}$ & $\begin{array}{c}\text { No } \\
\text { predi- } \\
\text { ction }\end{array}$ & $\begin{array}{c}\text { Time } \\
\text { series(h) }\end{array}$ & $\begin{array}{l}\text { No predi- } \\
\text { ction }\end{array}$ & $\begin{array}{c}\text { Time } \\
\text { series(h) }\end{array}$ & $\begin{array}{l}\text { No predi- } \\
\text { ction }\end{array}$ \\
\hline 1 & 10.8 & 13 & 21.4 & 25 & 7 & 37 & 10.3 \\
\hline 2 & 16.4 & 14 & 26.6 & 26 & 4.6 & 38 & 37.6 \\
\hline 3 & 8 & 15 & 22.8 & 27 & 6.8 & 39 & 28 \\
\hline 4 & 9.8 & 16 & 31.3 & 28 & 7.4 & 40 & 28.2 \\
\hline 5 & 21.8 & 17 & 49.1 & 29 & 37.5 & 41 & 51.9 \\
\hline 6 & 23.8 & 18 & 83.1 & 30 & 25.4 & 42 & 21.2 \\
\hline 7 & 22.2 & 19 & 24 & 31 & 39.8 & 43 & 7.2 \\
\hline 8 & 51 & 20 & 60.6 & 32 & 27.6 & 44 & 11 \\
\hline 9 & 23.6 & 21 & 41.1 & 33 & 24.2 & 45 & 21.5 \\
\hline 10 & 7.7 & 22 & 26.5 & 34 & 14 & 46 & 23.6 \\
\hline 11 & 21.1 & 23 & 7.6 & 35 & 28.7 & 47 & 22.1 \\
\hline 12 & 8 & 24 & 5.9 & 36 & 32.2 & 48 & 6.7 \\
\hline
\end{tabular}


Meanwhile, if power fluctuation of wind farm can be limited within $20 \%$ with a battery energy storage system, the wind farm will participate in the dispatching plan of power system, which will enhance system security and improve the economics of the system operation.

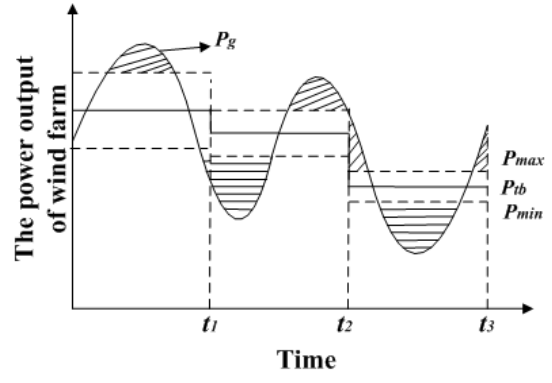

a) With power prediction

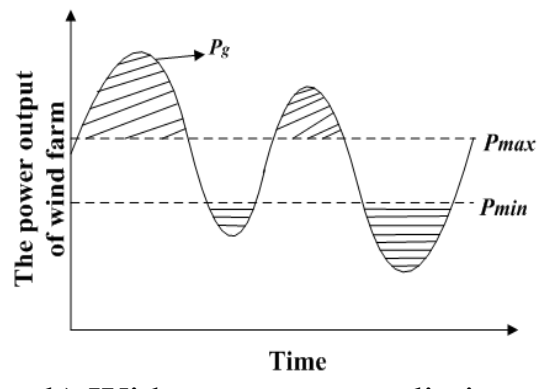

b) With no power prediction

Figure 4. The power fluctuation in certain period of a wind farm

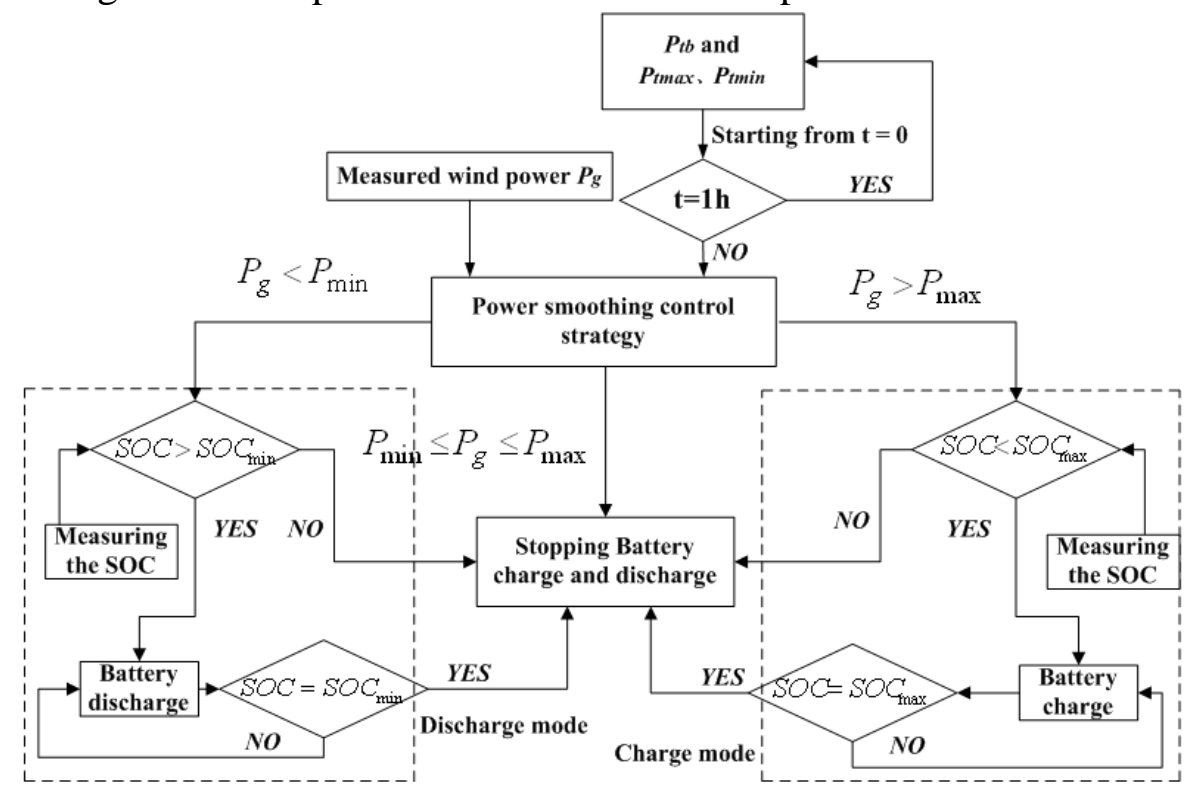

Figure 5. Charging/discharging modes of battery under smooth control cycle

Fig. 4 a) shows the power fluctuation which is based on prediction reference of wind power. Fig. 4 b) is a schematic diagram of power fluctuation with no power prediction. In Fig. 4 a), $P_{t b}$ is the power output of the wind farm, $0 \sim t_{1}, t_{1} \sim t_{2}, t_{2} \sim t_{3}$ are the forecast time period, respectively. Wind power prediction values corresponding to this three periods are $P_{t b l}, P_{t b l}, P_{t b l}$, respectively. Power smoothing upper limit is $P_{\max }$ and taken as $(1+0.5 \beta) P_{t b}$, While $P_{\min }$ is the power smoothing lower limit and taken as $(1-0.5 \beta) P_{t b}$.In the picture, shaded part above $P_{\max }$ is charging capacity of battery; While the shaded part below $P_{\min }$ is discharging capacity of battery. Wind power output curve after smoothing with no prediction is shown in Fig.4 b). Comparing with Fig.4 a) and b), it is clear that the smooth area is much greater with no wind power prediction power reference, which indicates that more battery capacity is required, as well as greater charging and discharging capacity of battery in one time.

Battery state of charge (SOC) has an important impact on the smooth control of wind power. SOC is defined as the percentage of the total capacity $Q_{b}$ that the remaining capacity $Q_{t}$ of battery energy storage system takes up in this paper, that is

$$
S O C=\frac{Q_{t}}{Q_{b}} \times 100 \%
$$

Taking battery life into account in control, we make $S O C_{\max }=90 \%, S O C_{\min }=10 \%$.

The smooth control strategy of wind power output proposed in this paper which based on taking the predictive value of wind power as the power reference and taking the change of SOC into account is shown in Fig.5.Fig.5 is a battery charging or discharging mode control within a smooth cycle. Taking the predictive value of wind power in a certain period as a reference, we calculate the power smoothing upper and lower limit based on above method, and then compare the measured power 
output of wind farm and the power smoothing upper and lower limit to determine the operation model that the battery takes. And time sequence t of control will be timed at the moment. If $P_{\max } \leq P_{g} \leq P_{\max }$,

The battery will not enter the charging and discharging mode; When $P_{g} \leq P_{\min }$, the battery will step into charging mode. In this period, battery will achieve discharging as long as $S O C>S O C_{\text {min }}$, otherwise it will stop discharging; When $P_{g} \geq P_{\max }$, battery will step into charging mode. In this period, battery will achieve charging as long as $S O C<S O C_{\max }$, otherwise it will stop charging. The time length of Battery charging or discharging within each cycle depends on the time length of the smooth control cycle and the SOC. When time sequence t of control equals to the time length of smooth control cycle, it will step into the next smooth control cycle.

\subsection{The power smooth control strategy of battery energy storage system based on the hybrid power prediction}

In the power smooth control strategy of battery energy storage system based on the hybrid power prediction, BESS is usually taken as smooth control components. It can also participate in the system peak clipping tasks in short time when system has the emergency of peaking demand. BESS will select the power control strategy of predicted battery energy storage system based on hybrid power.

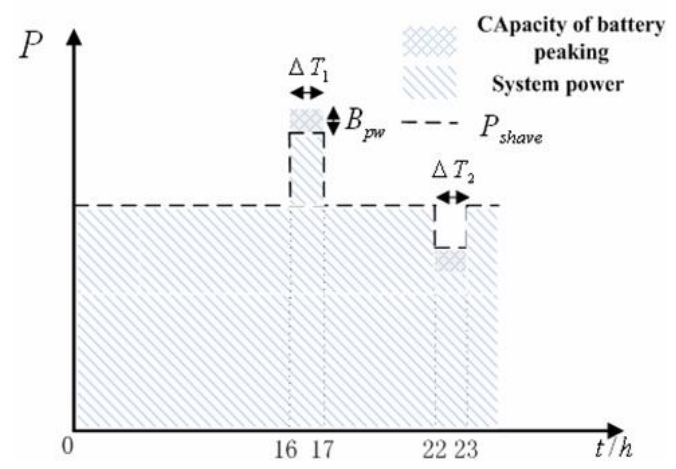

Figure 6. Curve of load demand and peaking need

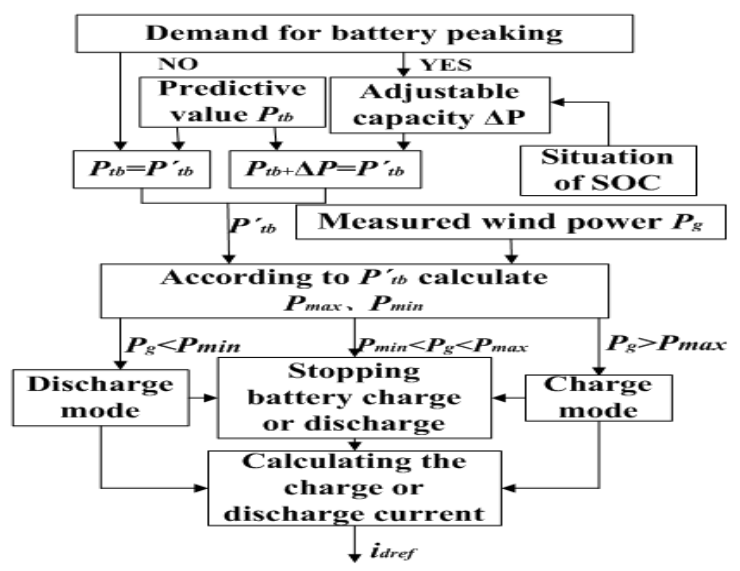

Figure 7. BESS control based on the hybrid power prediction reference

Fig.6 places the diagram of typical daily load demand and peaking demand. $P_{\text {shave }}$ is the sum of system power, wind power and conventional peaking power. Usually, the system power and wind power can meet the load demand. However, the system has peaking demand in the daily 16-17 o'clock when users' demand is up to the highest peak. Then, discharging of BESS can be used to participate in the peak dispatching of system when the spare capacity of conventional system is insufficient. In the period of daily 22-23 o'clock, as the load demand is the least and wind power resources are abundant, BESS can be charged by making full use of wind power resources. $P_{p w}$ is power of BESS to participate in peak shaving of the system, which is defined as the difference between load demand $p$ and $P_{\text {shave }}$. $\Delta T i$ is battery charging and discharging time, $B_{\text {cap }}$ battery charging and discharging capacity. The relationship among $\Delta T i, P_{p w}$ and $B_{c a p}$ can be expressed as.

$$
B_{\text {cap }}=\frac{P_{p w} \cdot \Delta T_{i}}{U_{\text {bess }}}
$$


Where, $U_{\text {bess }}$ is rate voltage of BESS. Battery is in the discharging state when $i=1$, and in the charging state when $i=2$.

Based on prediction reference of hybrid power, the control strategy of BESS which has the function of controlling the power of smoothing and peak shaving is shown in Fig.7. When the system has no battery peaking demand, the reference power $P_{t b}^{\prime}$ can be obtained directly by the predictive value of wind power. When the system has battery peaking demand and SOCmin $<\mathrm{SOC}<\mathrm{SOCmax}$, it is necessary to firstly identify adjustable power Ppw of battery, then identify the reference power $P_{t b}^{\prime}$ depending on the sum of predictive value of wind power and Ppw. In the view of the controlling requirement of fluctuation rate 20\%, the upper limit Pmax and lower limit Pmin of smoothing control can be formed by $P_{t b}^{\prime}$, then identify the charging and discharging mode of battery according to the comparison of $P_{t b}^{\prime}$ and measured power output of wind power, and finally form the dynamic reference active current idref. Which is taken as active decoupling control component of AC/DC converter for BESS, namely the controlling reference of id. When the battery peaking and smoothing are restricted by the SOC of battery (see Fig.5), the battery will stop charging or discharging.

\section{Conclusion}

According to the hourly prediction results of wind power and load power demand, this paper presents a power smooth control strategy of battery energy storage based on the hybrid power prediction. The simulation studies show that: Firstly, the BESS based on power prediction can significantly improve the fluctuation rate of active wind power output within $20 \%$. Secondly, the BESS based on power prediction enables power output and forecasting power of wind farm to be more consistent.

\section{References}

[1]. Li Feng, Lu Yichuan. Influences of large-scale wind energy converters on transmission systems. Electric Power, 2006, 39(11):80-84.

[2]. Zhang Liying, Ye Tinglu, Xin Yaozhong, et al. Problems and Measures of Power Grid Accommodating Large Scale Wind Power[J]. Proceedings of the CSEE, 2010, 30(25):1-9.

[3]. Sun Yuanzhang, Wu Jun, Li Guojie, et al. Dynamic Economic Dispatch Considering Wind Power Penetration Based on Wind Speed Forecasting and Stochastic Programming [J]. Proceedings of the CSEE, 2009, 29(4):41-47.

[4]. Ronan D, Eleanor D, Mark O'. System operation with a significant wind power penetration[C]. IEEE Power Engineering Society General Meeting, Denver, 2004.

[5]. The Standard of Wind Power Technology [S].Beijing: National Energy Board, 2009. 